\title{
Early health technology assessment of future clinical decision rule aided triage of patients presenting with acute chest pain in primary care
}

\author{
Robert T.A. Willemsen ${ }^{1}$, Michelle M.A. Kip ${ }^{2}$, Hendrik Koffijberg ${ }^{2}$, Ron Kusters ${ }^{2,3}$, Frank Buntinx ${ }^{1,4}$, \\ Jan F.C. Glatz ${ }^{5}$, Geert Jan Dinant ${ }^{1}$ and The 'RAPIDA' - Study Team ('RAPIDA': RAPid Test for Investigating \\ Complaints Possibly Due to Acute Coronary Syndrome) \\ ${ }^{1}$ Department of Family Medicine, Maastricht University, Maastricht, The Netherlands \\ ${ }^{2}$ Department of Health Technology and Services Research, MIRA Institute for Biomedical Technology and Technical \\ Medicine, University of Twente, Enschede, The Netherlands \\ ${ }^{3}$ Department of Clinical Chemistry and Hematology, Jeroen Bosch Hospital, 's-Hertogenbosch, The Netherlands \\ ${ }^{4}$ Department of Family Medicine, KU Leuven, Leuven, Belgium \\ ${ }^{5}$ Department of Genetics \& Cell Biology, Maastricht University, Maastricht, The Netherlands
}

\begin{abstract}
The objective of the paper is to estimate the number of patients presenting with chest pain suspected of acute coronary syndrome (ACS) in primary care and to calculate possible cost effects of a future clinical decision rule (CDR) incorporating a point-of-care test (PoCT) as compared with current practice. The annual incidence of chest pain, referrals and ACS in primary care was estimated based on a literature review and on a Dutch and Belgian registration study. A health economic model was developed to calculate the potential impact of a future CDR on costs and effects (ie, correct referral decisions), in several scenarios with varying correct referral decisions. One-way, two-way, and probabilistic sensitivity analyses were performed to test robustness of the model outcome to changes in input parameters. Annually, over one million patient contacts in primary care in the Netherlands concern chest pain. Currently, referral of eventual ACS negative patients (false positives, FPs) is estimated to cost $€ 1,448$ per FP patient, with total annual cost exceeding 165 million Euros in the Netherlands. Based on 'international data', at least a $29 \%$ reduction in FPs is required for the addition of a PoCT as part of a CDR to become cost-saving, and an additional €16 per chest pain patient (ie, 16.4 million Euros annually in the Netherlands) is saved for every further $10 \%$ relative decrease in FPs. Sensitivity analyses revealed that the model outcome was robust to changes in model inputs, with costs outcomes mainly driven by costs of FPs and costs of PoCT. If PoCT-aided triage of patients with chest pain in primary care could improve exclusion of ACS, this CDR could lead to a considerable reduction in annual healthcare costs as compared with current practice.
\end{abstract}

Key words: biomarkers; cardiovascular disease; clinical decision rule; cost effects; emergency medicine; primary care

Received 1 November 2016; revised 25 September 2017; accepted 1 October 2017;

first published online 18 December 2017

Correspondence to: Dr Robert T. A. Willemsen, Department of Family Medicine, Maastricht University, P. Debyeplein 1, Maastricht. PO box 616, 6200 MD Maastricht, The Netherlands. Email: robert.willemsen@maastrichtuniversity.nl

\section{Background}

A clinical decision rule (CDR) based on history and physical examination to safely rule out acute coronary syndrome (ACS) in primary care is not

(C) Cambridge University Press 2017 
available (Grijseels et al., 1996; Winters and Katzen, 2006; Body et al., 2010; Gencer et al., 2010; Bosner et al., 2013). Therefore, in primary care, up to $73 \%$ of patients with new or altered chest pain are immediately referred by the GP to the emergency department (Bruins Slot et al., 2013). However, only a minority of those patients (up to $26 \%$ in literature) are subsequently diagnosed with an acute life threatening disease, for example ACS ('true referrals' or 'true positives' (TPs)) (Chambers and Bass, 1998; Buntinx et al., 2001; Kohn et al., 2005; Hocaoglu et al., 2008; Bruins Slot et al., 2013). Patients that were referred and were found to be ACS negative ('false referrals' or 'false positives' (FPs)) were diagnosed with alternative diseases with advantageous courses (Buntinx et al., 2001; Kohn et al., 2005). In this context, the term 'false' is used to indicate a referral in absence of ACS afterwards. The referral itself however is undisputed, as it is the result of a GP unable to exclude a potentially life threatening disease. On the other hand, incidentally, ACS is present in patients that were initially not referred ('false nonreferrals' or 'false negatives'(FNs)) (Buntinx et al., 2001; Kohn et al., 2005).

ACS negative referrals (FPs) pose a significant burden on healthcare resources, and reduction of FPs can lead to increased patient comfort, while decreasing costs (Graff et al., 1997; Dumville et al., 2007; Mourad et al., 2013). Therefore, specificity of a future CDR for ACS should be higher - and sensitivity should at the least be maintained - as compared with current practice that is based on a GPs' clinical judgement only. Recently, the efficiency of similar diagnostic processes in primary care was improved by introducing a cost-effective CDR, combining point-of-care tests (PoCTs) with clinical findings, leading to less prescription of unnecessary antibiotics in lower respiratory tract infections and less unnecessary referral for suspected pulmonary embolism (Cals et al., 2011; Geersing et al., 2012; Little et al., 2013).

The availability of a validated CDR, incorporating a PoCT measuring a biomarker of myocardial damage (eg, high-sensitive troponin (hsTn) or heart-type fatty acid binding protein (H-FABP)) is anticipated, however not yet available (Nilsson et al., 2013; Glatz and Mohren, 2013; Glatz and Renneberg, 2014; Willemsen et al., 2014, 2015). The majority of GPs expect future PoCTs to be of added value in ruling out ACS (Kip et al., 2017).

\section{Objectives}

(1) To estimate the number of patients with chest pain in primary care, their referral rates and the incidence of ACS among these patients

(2) To assess the minimum required reduction in ACS negative referrals (FPs) due to a future CDR, incorporating clinical findings and a PoCT, to become cost-saving, assuming that the number of non-referrals among ACS patients (FNs) equals current practice

(3) To assess the impact of a relative decrease in ACS negative referrals (FPs), with decrements of $10 \%$

(4) To assess the combined impact of simultaneously varying the referrals among non-ACS patients (FPs) and the costs of the PoCT, to determine which combinations are expected to save costs

\section{Methods}

\section{Estimation of annual patient numbers based on literature}

International data and a Dutch registration study were used as separate sources to estimate numbers of true and false referrals (referred to as true and false positives respectively (TPs and FPs)) as well as true and false non-referrals (referred to as true and false negatives respectively (TNs and FNs)) in primary care in the Netherlands (Hoorweg et al., 2017). The international data were obtained through an extensive literature search. Those data will be referred to as 'international data', and will be used as the base case scenario in the remainder of this paper. However, as registration studies are rare, it was expected that part of the data were to be derived from studies describing relevant data that were primarily designed to meet other objectives. Therefore, we searched PubMed and Embase from January 1989 to May 2017 for chest complaints in primary care (see Supplementary Material Figure S1 for an overview of the literature search and strategy). Articles assumed relevant based on title/abstracts were read in order to select all studies supplying relevant data on the incidence of chest complaints in primary care, referral rates, and final diagnoses (when available). Additional relevant articles were identified from the references in these selected 
papers. Besides these sources, we used Dutch registry data (governmental data, data from the Dutch Heart Foundation and data from the Dutch Central Statistics Agency) (Okkes et al., 2005; Academic Hospital Maastricht, 2013; Catholic University Leuven, 2013; Dutch Heart Foundation, 2013; Centraal Bureau voor de Statistiek (CBS), 2014a; 2014b; 2014c; 2014d). Data from the literature review as well as from the Dutch registries were pooled and mean values with $95 \%$ confidence intervals $(95 \% \mathrm{CI})$ were calculated. In most cases, the included studies did not describe all probabilities in the patient pathway (eg, the set of studies that described the percentage of patients that is referred to secondary care, differed from the set of studies that described the proportion of ACS positive cases among those referred patients). Therefore, the sample sizes of the pooled estimates differed across the different parameters. Eventually, the pooled international data were translated to estimated referral rates and incidence of ACS in the Netherlands. As a second scenario to model the patient pathway of Dutch patients with chest pain in primary care, a Dutch/Belgian registration study was used, and this scenario will be referred to as 'NL and B data' (Hoorweg et al., 2017).

\section{Model diagnostic process, resource use}

A health economic model was developed to estimate the costs of the full diagnostic work-up. Costs were estimated based on several sources (see Table 1), and expressed in 2016 Euros (CBS, 2016). The analysis was performed from a healthcare perspective, incorporating all direct medical costs that occur from the moment a patient presents with chest pain in primary care, until the patient was either referred to and diagnosed and treated in secondary care, or sent home following the GP consultation (without referral). As this time horizon is less than one year, discounting of costs and effects was not required. Calculations were performed using unit costs for assessment in primary care including PoCT testing, ambulance transport to the hospital, and assessment in secondary care. Exclusion of ACS by a GP costs $€ 18$ without PoCT, and increases to $€ 63$ when cost for usage of a PoCT of $€ 45$ is included (based on the expected price of a H-FABP PoCT which is currently in development). The cost for every patient that is assessed in a hospital for cardiac analysis with and without the eventual presence of an underlying ACS is estimated at €5735 and €1426 respectively, including hospital transport by ambulance.

\section{Outcome measures}

The primary effectiveness measure was defined as the percentage of patients in whom ACS (including both unstable angina (UA) and acute myocardial infarction (AMI)) was correctly diagnosed or excluded when using the CDR as compared with current practice. The incremental cost-effectiveness ratio (ICER) was therefore expressed as incremental costs per patient when using a CDR (including PoCT), as compared with current practice, and divided by the difference in the number of patients in whom the correct referral decision is made in both work-ups.

Table 1 Model input: cost data

\begin{tabular}{|c|c|c|}
\hline Parameter & Value $[95 \% \mathrm{Cl}]$ & Distribution \\
\hline Consultation at tariff GP (double)* & $€ 18.00[€ 10.18-27.93]$ & Gamma \\
\hline PoCT (including finger prick needle, and VAT)** & $€ 45.00[€ 26.08-69.52]$ & Gamma \\
\hline $\begin{array}{l}\text { Ambulance transport medium to high urgency (medical } \\
\text { personnel A1/A2 drive, overhead costs call center, and VAT)*** }\end{array}$ & $€ 750.00[€ 429.70-1,172.51]$ & Gamma \\
\hline $\begin{array}{l}\text { Analysis CCU, no ACS (diagnostic tests, medical personnel, } \\
\text { hospital stay one to two days) }{ }^{* * * *}\end{array}$ & $€ 676.00[€ 386.75-1054.49]$ & Gamma \\
\hline $\begin{array}{l}\text { Analysis CCU, ACS present (diagnostic tests, medical personnel, } \\
\text { hospital stay } 3 \text { days, } \mathrm{PCl})^{* * *}\end{array}$ & $€ 4985.00[€ 2823.36-7673.56]$ & Gamma \\
\hline
\end{tabular}

Cost prices for relevant events in in- or excluding ACS in The Netherlands. Cost prices are based on the following sources: double consultation price GP in The Netherlands $(*)$, estimations from manufacturer $(* *)$, cost price requested at large ambulance service in South of The Netherlands $(* * *)$, average diagnosis-treatment combination tariffs of considerable number of Dutch hospitals of varying type (small, large, academic, urban, rural) $\left(^{* * *}\right)$.

$95 \% \mathrm{Cl}=95 \%$ confidence interval; $\mathrm{ACS}=$ acute coronary syndrome; $\mathrm{CCU}=$ coronary care unit; $\mathrm{H}-\mathrm{FABP}=$ heart-type fatty acid binding protein; $\mathrm{PCl}=$ percutaneous coronary intervention; $\mathrm{PoCT}=$ point-of-care test; $\mathrm{VAT}=$ value-added tax. 


\section{One- and two-way sensitivity analysis}

A two-way deterministic sensitivity analysis was performed to obtain insight into the combined impact of simultaneously varying the cost of the PoCT and the \%FPs (Briggs et al., 2006). For subsequent analysis (ie, one-way and probabilistic sensitivity analyses), the minimum required relative decrease in FPs to obtain a strategy that is cost-saving compared with current practice was applied in the scenarios with PoCT (while assuming that costs of the PoCT remain unaffected). Following this, to identify which individual cost parameters drive the model outcome, given fixed costs of the PoCT and the minimum required relative decrease in FPs, we conducted a one-way deterministic sensitivity analysis (Briggs et al., 2006). In the one-way sensitivity analysis, the impact of a $25 \%$ decrease and increase in all cost input parameters on the costs per patient presenting with suspected ACS in primary care was analysed. As the impact on FP referrals in the CDR + PoCT strategy was arbitrarily chosen (based on the minimum required reduction in FPs), it was decided to only incorporate the impact on costs in this one-way sensitivity analysis. In addition, this avoids double counting, as both the numerator and the denominator of the ICER are affected by a change in correct referral decisions.

\section{Probabilistic sensitivity analysis}

Distributions were assigned to all model parameters (Briggs et al., 2006). Subsequently, random samples were drawn for all model input parameters simultaneously. An overview of the type of distribution used for each input parameter, as well as the accompanying $95 \%$ confidence intervals $(95 \% \mathrm{CI})$ is provided in Tables 1 and 2 . A probabilistic sensitivity analysis (PSA) based on Monte Carlo simulation with 10000 samples was performed to determine the effect of joint uncertainty in all model input parameters on model outcome.

\section{Results}

\section{Estimation of relevant patient numbers}

In our literature search, 1900 articles were assessed. The majority of articles were not

Table 2 Model input: effectiveness data for three different base cases

\begin{tabular}{|c|c|c|c|c|c|}
\hline \multirow[b]{2}{*}{$\begin{array}{l}\text { Scenario (estimated annual } \\
\text { number of chest pain patients } \\
\text { for the Netherlands }[95 \% \mathrm{Cl}] \text { ) }\end{array}$} & \multicolumn{2}{|l|}{ Referred } & \multicolumn{2}{|l|}{ Not referred } & \multirow[b]{2}{*}{ Distribution } \\
\hline & & & & & \\
\hline $\begin{array}{l}\text { International data* } \\
(n=1054729 \\
\left.\left[\begin{array}{l}1 \\
047881-1\end{array} 061578\right]\right)\end{array}$ & $3.4 \%[2.8-4.0 \%]$ & $10.8 \%[10.2-11.5 \%]$ & $1.5 \%[0.8-2.2 \%]$ & $84.3 \%$ [83.5-85.0\%] & Beta \\
\hline $\begin{array}{l}\text { NL and B data** }(n=862960) \\
\text { Combined data*** } \\
(n=1054729 \\
\quad[1047881-1068427])\end{array}$ & $\begin{array}{l}6.1 \%[4.0-7.9 \%] \\
6.8 \%[5.5-7.0 \%]\end{array}$ & $\begin{array}{c}8.1 \%[6.0-11.1 \%] \\
21.9 \%[21.6-23.3 \%]\end{array}$ & $\begin{array}{l}0.3 \%[0.0-2.5 \%] \\
0.3 \%[0.0-1.7 \%]\end{array}$ & $\begin{array}{l}85.5 \%[80.6-89.1 \%] \\
71.0 \%[69.6-71.7 \%]\end{array}$ & $\begin{array}{l}\text { Beta } \\
\text { Beta }\end{array}$ \\
\hline \multicolumn{6}{|c|}{ 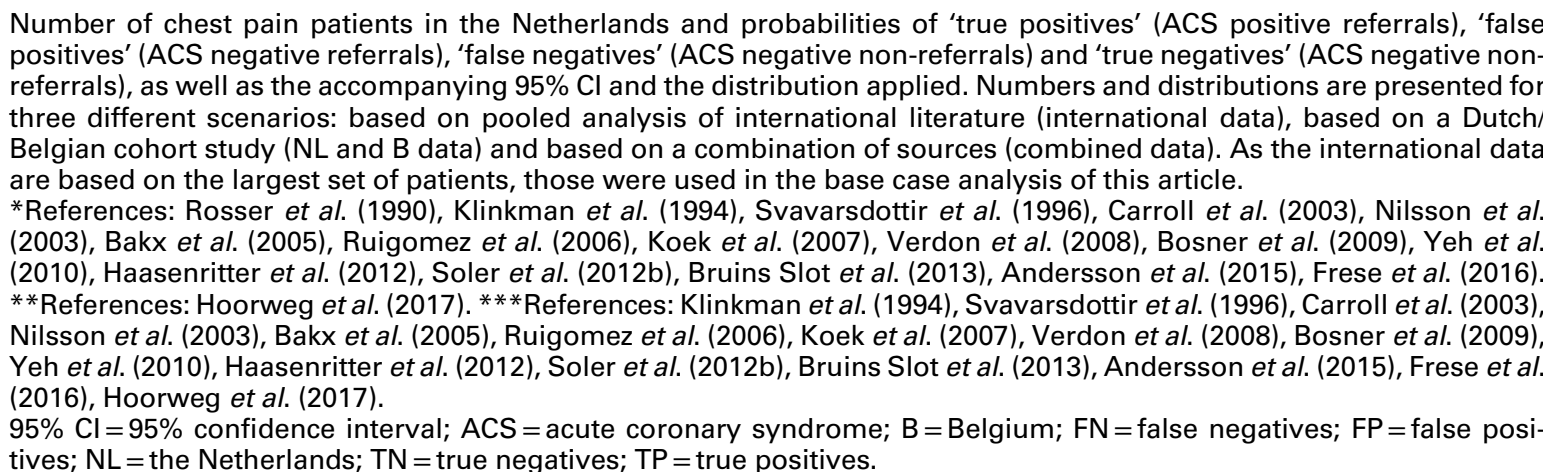 } \\
\hline
\end{tabular}


considered relevant after screening the title and abstract. Of the remaining 17 articles, three additional articles were eliminated after full text evaluation, since no relevant data were obtainable from these papers (Sox et al., 1990; Soler et al., 2012a; Haasenritter et al., 2015). Two articles reported as references in the remaining 14 articles were added, resulting in a final number of 16 articles that were included (Supplementary Material Figure S1) (Rosser et al., 1990; Klinkman et al., 1994; Svavarsdottir et al., 1996; Nilsson et al., 2003; Carroll et al., 2003; Bakx et al., 2005; Ruigomez et al., 2006; Koek et al., 2007; Verdon et al., 2008; Bosner et al., 2009; Yeh et al., 2010; Haasenritter et al., 2012; Soler et al., 2012b; Bruins Slot et al., 2013; Andersson et al., 2015; Frese et al., 2016). In addition, data from regional and national Dutch and Belgian databases were used (Okkes et al., 2005; Academic Hospital Maastricht, 2013; Catholic University Leuven, 2013; Dutch Heart Foundation, 2013; CBS, 2014a; 2014b; 2014c; 2014d). In Supplementary Material Table S1, all relevant data representing parts of the patient flow of patients with chest complaints, found in the selected articles and databases, are presented. All data were converted to absolute patient numbers in the Netherlands (Supplementary Material Table 2). Numbers of TPs, FPs, TNs and FNs were calculated (see Table 2). Besides the estimated patient numbers based on the two previously defined data sets (ie, base case 'international data' and the 'NL and B data'), a third scenario (referred to as 'combined data') was defined. This data set was based on the international data, although one article was excluded because the health system and time setting in which this study was performed were considered not comparable with the current health system in the Netherlands (Rosser et al., 1990). In addition, in this scenario the incidence of FNs was based on the 'NL and B data', as the incidence of FNs in the base case 'international data' seemed higher than observed in Dutch daily practice (Hoorweg et al., 2017). All analyses were performed for each of these three scenarios, with the international data used as base case, as these data are based on the largest set of patients. The main results based on the 'NL and B data' and the 'combined data' are also presented in the text of this paper, the accompanying figures can be found in the supplementary webonly figures.

Primary Health Care Research \& Development 2018; 19: 176-188

\section{Patient flow, GP's sensitivity and specificity in current practice}

The results of the literature review indicate that annually in primary care in the Netherlands, 1054729 [95\% CI 1047881-1061578] patients consult a GP for chest pain. The referral rate among these patients was found to be $14.2 \%$ [95\% CI 14.0-14.4]. Sensitivity and specificity of a GPs judgement in the current setting (not aided by a CDR), are 69 and $89 \%$ for the 'international', 95 and $91 \%$ for 'NL and B', and 96 and $76 \%$ for the 'combined data', respectively.

\section{Required reduction of ACS negative referrals (FPs) due to a future CDR, effect of further reduction of FPs}

When the cost price of a future PoCT is set at $€ 45$, the minimum required relative reductions in FPs for the PoCT strategy to become cost-saving are $29.0,39.5$ and $14.5 \%$ for the international data', the 'NL and B data', and the 'combined data', respectively (see Figure 1 and Supplementary Material Figures S2 and S3). In Table 3, the impact of a further relative reduction in FP rates on costs is shown for all three scenarios. For every additional absolute $10 \%$ reduction in \%FPs, average additional cost savings per patient are $€ 16$ when using 'international data', €12 for 'NL and $\mathrm{B}$ data' and $€ 31$ for 'combined data' per chest pain patient.

\section{Impact on health outcomes and costs}

The minimum required relative decrease in \% FPs, as obtained from the two-way SA, was used as input into the PSA, while assuming that costs of the PoCT would remain unchanged (ie, €45). The results of this analysis on the average total costs (both per patient as well as the total costs in the Netherlands), are shown in Table 4. To visualize the constitution of those total costs, results are split up into costs that are attributable to TPs, FPs, FNs and TNs, and as the corresponding fraction of total costs. The result of the 10000 Monte Carlo simulations is shown in Figure 2 for the 'international data', whereas results for the 'NL and B data' and 'combined data' are shown in Supplementary Material Figures S4 and S5, respectively. 


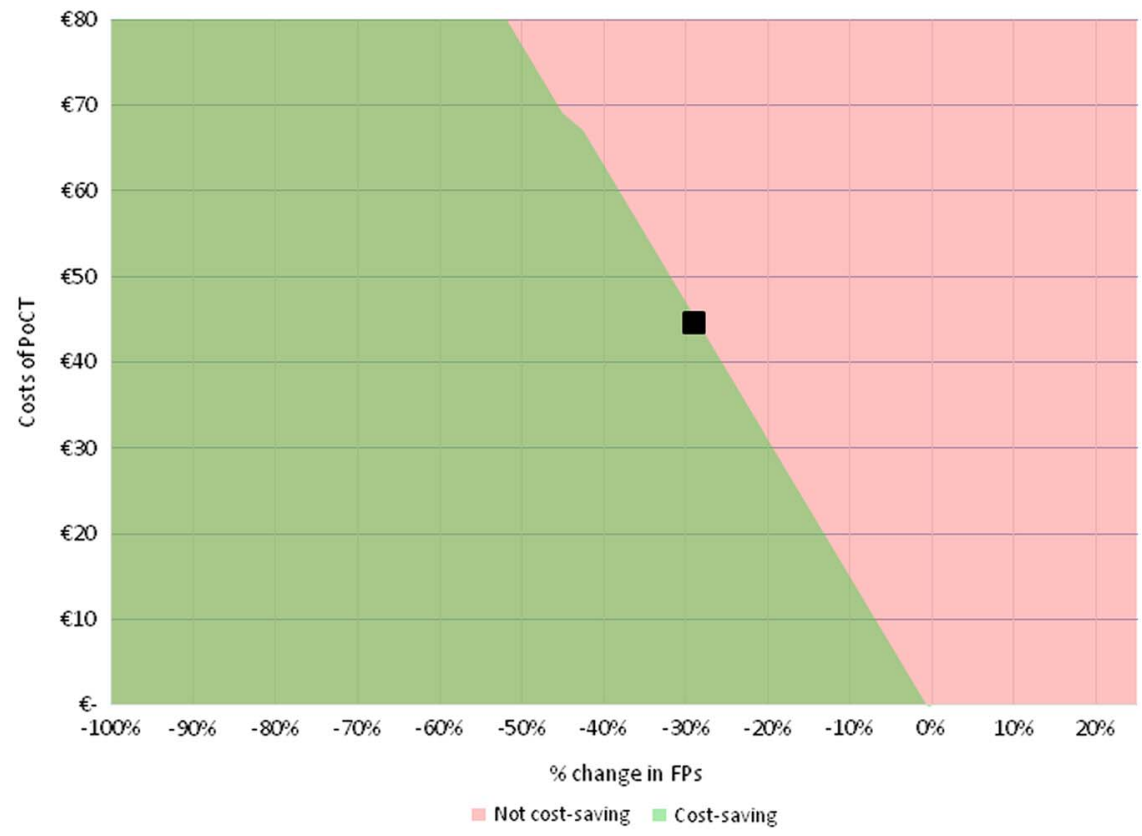

Figure 1 Two-way SA for 'international data'. Deterministic two-way SA showing the combined effect of a relative reduction in ACS negative referrals (FPs, on $x$-axis), and of a variation in costs of a PoCT (on $y$-axis), on the difference in total costs between PoCT and current practice (ie, without PoCT). The analysis was performed based on the 'international data'. When assuming that PoCT would only impact the \%FPs and incur costs of the PoCT test (and leave all other model input parameters unaffected), a relative reduction of at least $29.0 \%$ in FPs is required to make the PoCT strategy become cost-saving (as represented by the black square, assuming a cost price of a PoCT test of $€ 45.00$ ). ACS $=$ acute coronary syndrome; FPs = false positives; PoCT = point-of-care test; two-way SA = two-way sensitivity analysis.

Table 3 Effect of a stepwise reduction of acute coronary syndrome (ACS) negative referrals (FPs) on costs

\begin{tabular}{|c|c|c|c|c|c|c|}
\hline \multirow[b]{2}{*}{ Change in \%FPs } & \multicolumn{2}{|c|}{$\begin{array}{l}\text { International data } \\
\text { Base case without POC: } € 366.57 \\
\text { Base case with POC: } € 411.71\end{array}$} & \multicolumn{2}{|c|}{$\begin{array}{l}N L \text { and } B \text { data } \\
\text { Base case without POC: } € 485.01 \\
\text { Base case with POC: } € 530.14\end{array}$} & \multicolumn{2}{|c|}{$\begin{array}{l}\text { Combined } \\
\text { Base case without POC: } € 722.46 \\
\text { Base case with POC: } € 757.59\end{array}$} \\
\hline & Effect on costs & $\%$ effect & Effect on costs & $\%$ effect & Effect on costs & $\%$ effect \\
\hline$-100 \%$ & $€-110.20$ & $-30.1 \%$ & $€-71.93$ & $-14.8 \%$ & $€-286.05$ & $-39.6 \%$ \\
\hline$-90 \%$ & $€-94.66$ & $-25.8 \%$ & $€-60.22$ & $-12.4 \%$ & $€-236.73$ & $-32.8 \%$ \\
\hline$-80 \%$ & $€-79.13$ & $-21.6 \%$ & $€-48.52$ & $-10.0 \%$ & $€-205.41$ & $-28.4 \%$ \\
\hline$-70 \%$ & $€-63.60$ & $-17.4 \%$ & $€-36.81$ & $-7.6 \%$ & $€-174.09$ & $-24.1 \%$ \\
\hline$-60 \%$ & $€-48.07$ & $-13.1 \%$ & $€-25.10$ & $-5.2 \%$ & $€-142.77$ & $-19.8 \%$ \\
\hline$-50 \%$ & $€-32.53$ & $-8.9 \%$ & $€-13.40$ & $-2.8 \%$ & $€-111.46$ & $-15.4 \%$ \\
\hline$-40 \%$ & $€-17.00$ & $-4.6 \%$ & $€-1.69$ & $-0.3 \%$ & $€-80.14$ & $-11.1 \%$ \\
\hline$-30 \%$ & $€-1.47$ & $-0.4 \%$ & $€ 10.01$ & $+2.1 \%$ & $€-48.82$ & $-6.8 \%$ \\
\hline$-20 \%$ & $€ 14.07$ & $+3.8 \%$ & $€ 21.72$ & $+4.5 \%$ & $€-17.50$ & $-2.4 \%$ \\
\hline$-10 \%$ & $€ 29.60$ & $+8.2 \%$ & $€ 33.43$ & $+6.9 \%$ & $€ 13.81$ & $+1.9 \%$ \\
\hline $0 \%$ (base case) & $€ 45.13$ & $+12.3 \%$ & $€ 45.13$ & $+9.3 \%$ & $€ 45.13$ & $+6.2 \%$ \\
\hline
\end{tabular}

This table shows the impact of steps of a $10 \%$ relative decrease in FP referrals (deterministic). At the top of the table, the costs for each of the base case scenarios is shown, depending on whether the PoCT is used. Absolute and relative effects are given for all three scenarios ('international data', 'NL and B data' and 'combined data' respectively). If no reduction in FPs is achieved ( $0 \%$ change $=$ base case for all three scenarios where the PoCT is used) costs in all three scenarios will rise with the cost of a PoCT (€ 45.13), as compared with current daily practice where a PoCT is not used.

$\mathrm{ACS}=$ acute coronary syndrome; $\mathrm{B}=$ Belgium; $\mathrm{FP}=$ false positives; $\mathrm{NL}=$ the Netherlands; PoCT= point-of-care test. 
Table 4 Costs per patient, converted to patient numbers in the Netherlands

\begin{tabular}{|c|c|c|c|c|c|c|c|c|c|c|}
\hline \multirow[t]{3}{*}{ Scenario } & \multicolumn{4}{|l|}{ Referred } & \multicolumn{4}{|c|}{ Not referred } & \multirow[b]{3}{*}{$\begin{array}{l}\text { Costs per } \\
\text { patient }\end{array}$} & \multirow[b]{3}{*}{$\begin{array}{l}\text { Total costs in the } \\
\text { Netherlands }\end{array}$} \\
\hline & \multicolumn{2}{|l|}{ ACS (TP) } & \multicolumn{2}{|c|}{ No ACS (FP) } & \multicolumn{2}{|c|}{$\mathrm{ACS}(\mathrm{FN})$} & \multicolumn{2}{|c|}{ No ACS (TN) } & & \\
\hline & Costs & $\%$ & Costs & $\%$ & Costs & $\%$ & Costs & $\%$ & & \\
\hline $\begin{array}{l}\text { International } \\
\text { data* }\end{array}$ & $\begin{array}{l}€ 194.00 \\
(€ 116.35- \\
293.90)\end{array}$ & $52.9 \%$ & $\begin{array}{l}€ 157.22 \\
(€ 108.36- \\
215.09)\end{array}$ & $42.9 \%$ & $\begin{array}{l}€ 0.28 \\
(€ 0.12- \\
0.50)\end{array}$ & $0.1 \%$ & $\begin{array}{l}€ 15.25 \\
(€ 8.71- \\
23.66)\end{array}$ & $4.2 \%$ & $\begin{array}{l}€ 366.71 \\
(€ 268.07- \\
483.72)\end{array}$ & $\begin{array}{l}€ 385736500 \\
(€ 282739424- \\
510189897)\end{array}$ \\
\hline $\begin{array}{l}\mathrm{NL} \text { and } \mathrm{B} \\
\text { data }^{* *}\end{array}$ & $\begin{array}{l}€ 338.82 \\
(€ 182.95- \\
546.32)\end{array}$ & $71.3 \%$ & $\begin{array}{l}€ 120.88 \\
(€ 72.67- \\
184.89)\end{array}$ & $25.4 \%$ & $\begin{array}{r}€ 0.12 \\
(€ 0.00- \\
0.47)\end{array}$ & $0.0 \%$ & $\begin{array}{l}€ 15.40 \\
(€ 8.76- \\
23.87)\end{array}$ & $3.2 \%$ & $\begin{array}{l}€ 475.27 \\
(€ 296.30- \\
712.19)\end{array}$ & $\begin{array}{l}€ 400543692 \\
(€ 255691986- \\
614595666)\end{array}$ \\
\hline $\begin{array}{l}\text { Combined } \\
\text { data*** }\end{array}$ & $\begin{array}{l}€ 371.23 \\
(€ 224.78- \\
559.47)\end{array}$ & $52.5 \%$ & $\begin{array}{r}€ 322.99 \\
(€ 221.85- \\
445.24)\end{array}$ & $45.7 \%$ & $\begin{array}{l}€ 0.08 \\
(€ 0.00- \\
0.33)\end{array}$ & $0.0 \%$ & $\begin{array}{l}€ 12.79 \\
(€ 7.31- \\
20.00)\end{array}$ & $1.8 \%$ & $\begin{array}{l}€ 707.07 \\
(€ 518.55- \\
936.05)\end{array}$ & $\begin{array}{c}€ 767833684 \\
(€ 546928106- \\
987276217)\end{array}$ \\
\hline
\end{tabular}

This table presents where the average costs per patient are composed of, by splitting up those average costs into costs that are attributable to ACS positive referrals (TPs), ACS negative referrals (FPs), ACS positive non-referrals (FNs), and ACS negative non-referrals (TNs), as well as the accompanying percentage. Costs are given for all three base case scenarios ('international data', 'NL and B data' and 'combined data' respectively, without using PoCT), and based on the results of the probabilistic analysis.

* References: Rosser et al. (1990), Klinkman et al. (1994), Svavarsdottir et al. (1996), Carroll et al. (2003), Nilsson et al. (2003), Bakx et al. (2005), Ruigomez et al. (2006), Koek et al. (2007), Verdon et al. (2008), Bosner et al. (2009), Yeh et al. (2010), Haasenritter et al. (2012), Soler et al. (2012b), Bruins Slot et al. (2013), Andersson et al. (2015), Frese et al. (2016). **Reference: Hoorweg et al. (2017). ***References: Klinkman et al. (1994), Svavarsdottir et al. (1996), Carroll et al. (2003), Nilsson et al. (2003), Bakx et al. (2005), Ruigomez et al. (2006), Koek et al. (2007), Verdon et al. (2008), Bosner et al. (2009), Yeh et al. (2010), Haasenritter et al. (2012), Soler et al. (2012b), Bruins Slot et al. (2013), Andersson et al. (2015), Frese et al. (2016), Hoorweg et al. (2017).

$\mathrm{ACS}=$ acute coronary syndrome; $\mathrm{B}=$ Belgium; $\mathrm{FN}=$ false negatives; $\mathrm{FP}=$ false positives; $\mathrm{NL}=$ the $\mathrm{Netherlands;} \mathrm{PoCT}=$ point-of-care test; $\mathrm{TN}=$ true negatives; $\mathrm{TP}=$ true positives.

\section{Sensitivity of model outcome to changes in cost input parameters}

The sensitivity of the model outcome to changes in individual cost input parameters, was measured using a one-way sensitivity analysis. The results are shown in tornado diagrams (see Figure 3 for 'international data', Supplementary Material Figures S6 and S7 for 'NL and B data' and 'combined data'). Results indicate that the model outcome (expressed as cost per patient) is robust to changes in input parameters in all three scenarios. In addition, in all three scenarios, the model outcome is most sensitive to changes in costs of the PoCT, while it is less sensitive to changes in costs of ambulance transportation to the hospital and costs of analysis at the coronary care unit among FPs. As each patient is assumed to undergo one consultation at the GP, and because the probability of correctly diagnosing ACS was assumed not to be affected by the PoCT, the model outcome was not affected by changes in those input parameters.

\section{Discussion}

\section{Summary of main findings}

We estimated that in the Netherlands (population 17 million) annually $\sim 1$ million patient contacts with GPs are about chest pain. In $14 \%$ of these contacts, direct referral to a cardiologist is made. Eventually, no more than a quarter of these referred patient is diagnosed with ACS $(3.4 \%$ of all chest pain patients). As a result, $10.8 \%$ of all chest pain patients are referred while they eventually are diagnosed as not having ACS (FP). The estimated annual number of FPs in the Netherlands is 113911 , representing an economic burden of 162 million Euros. Improving triage of patients presenting with chest complaints to their GP could lead to a considerable reduction of FPs and thus to a reduction in both direct healthcare costs and patients' distress. We estimated the impact of a CDR incorporating a PoCT in this diagnostic process, on the accompanying costs and effects 


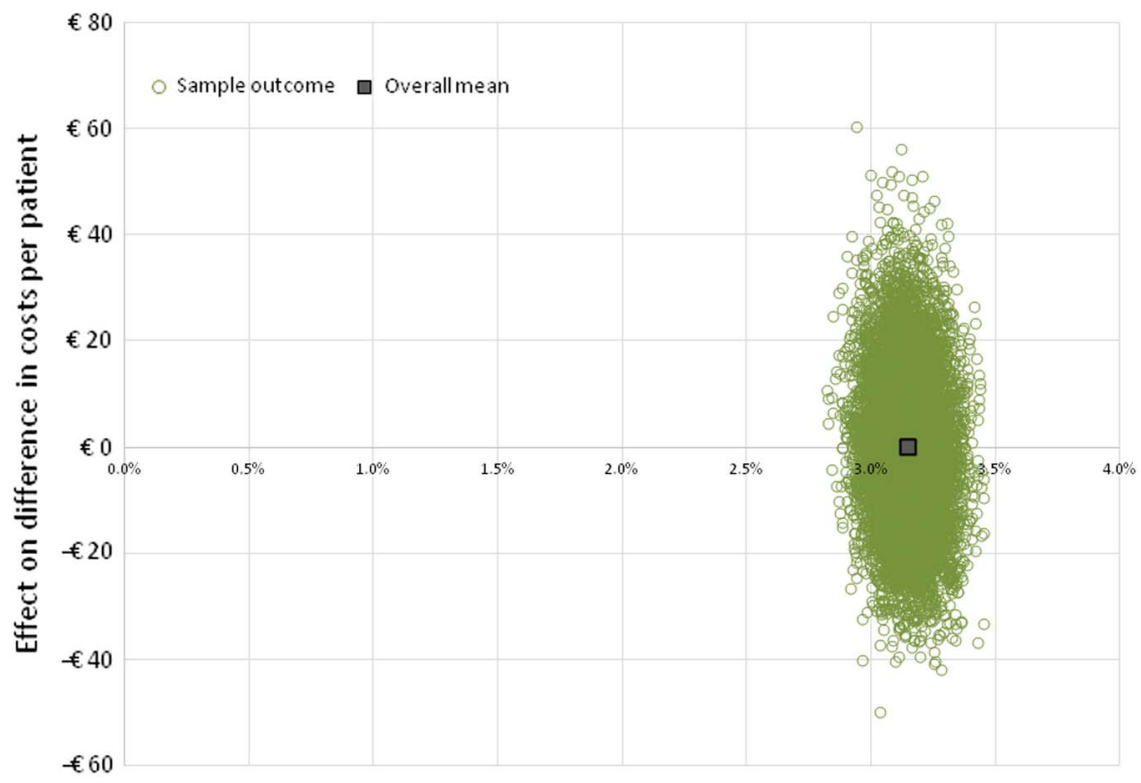

Effect on difference in $\%$ of ACS patients referred to hospital

Figure 2 Incremental cost-effectiveness plane based on 'international data'. This figure shows the result of 10000 model simulations (PSA), and the mean value, based on the international data. Costs of a PoCT are set at $€ 45$, and reduction of ACS negative referrals (FPs) is assumed to be $29.0 \%$ (cost-neutral as compared with current practice, see Figure 1). ACS=acute coronary syndrome; $\mathrm{FPs}=$ false positives; $\mathrm{PoCT}=$ point-of-care test; $\mathrm{PSA}=$ probabilistic sensitivity analysis.

(ie, number of patients in whom the correct referral decision is made). When using an estimated cost price of a PoCT of $€ 45$, introduction of such test would be cost-saving if a relative reduction in FPs of at least $29 \%$ is achieved. This would imply a reduction in percentage of unnecessary referred patients from 10.8 to $7.7 \%$. Such decrease would account for a cost saving of $€ 47,106,755$. Besides, for every $10 \%$ further reduction in \%FPs, beyond the reduction of $29 \%$ where cost neutrality was reached, €16 per chest pain patient - referred or not referred - is saved, accounting for an annual saved amount of $\sim 16$ million Euros in the Netherlands. In the two alternative scenarios, a required reduction in \%FPs of $39.5 \%$ for the 'NL and B data' and $14.4 \%$ for the 'combined data' was found. Such a reduction of FPs seems achievable when compared with results of similar studies in the field of suspected pulmonary embolism (Geersing et al., 2012). Yet, a lower cost price of a PoCT can attenuate the required reduction in FPs. Halving a PoCT's cost price to €22.50 leads to a minimum required reduction of FPs of only $14.5 \%$ for the PoCT to become cost-saving, when based on the 'international data'. Although the effect of preventing ACS negative referrals on societal costs has not been included in the current analysis, including those costs for both patients (and family or caregivers) would likely have increased the estimated cost savings that can be achieved by implementation of a PoCT-aided CDR.

\section{Sensitivity analysis}

In the one-way model-sensitivity analysis, the model outcome proved to be robust for varying the model input parameters with $-25 \%$ and $+25 \%$ from the base case value. However, the starting point for variation in costs was based on a cost price for the PoCT of $€ 45$, which was based on the cost prognosis of a PoCT H-FABP test in development, and results may have been different when differently priced or different cardiac marker based PoCTs (eg, PoCT troponin) would have been used. Therefore, a wider range of costs was applied in the two-way sensitivity 


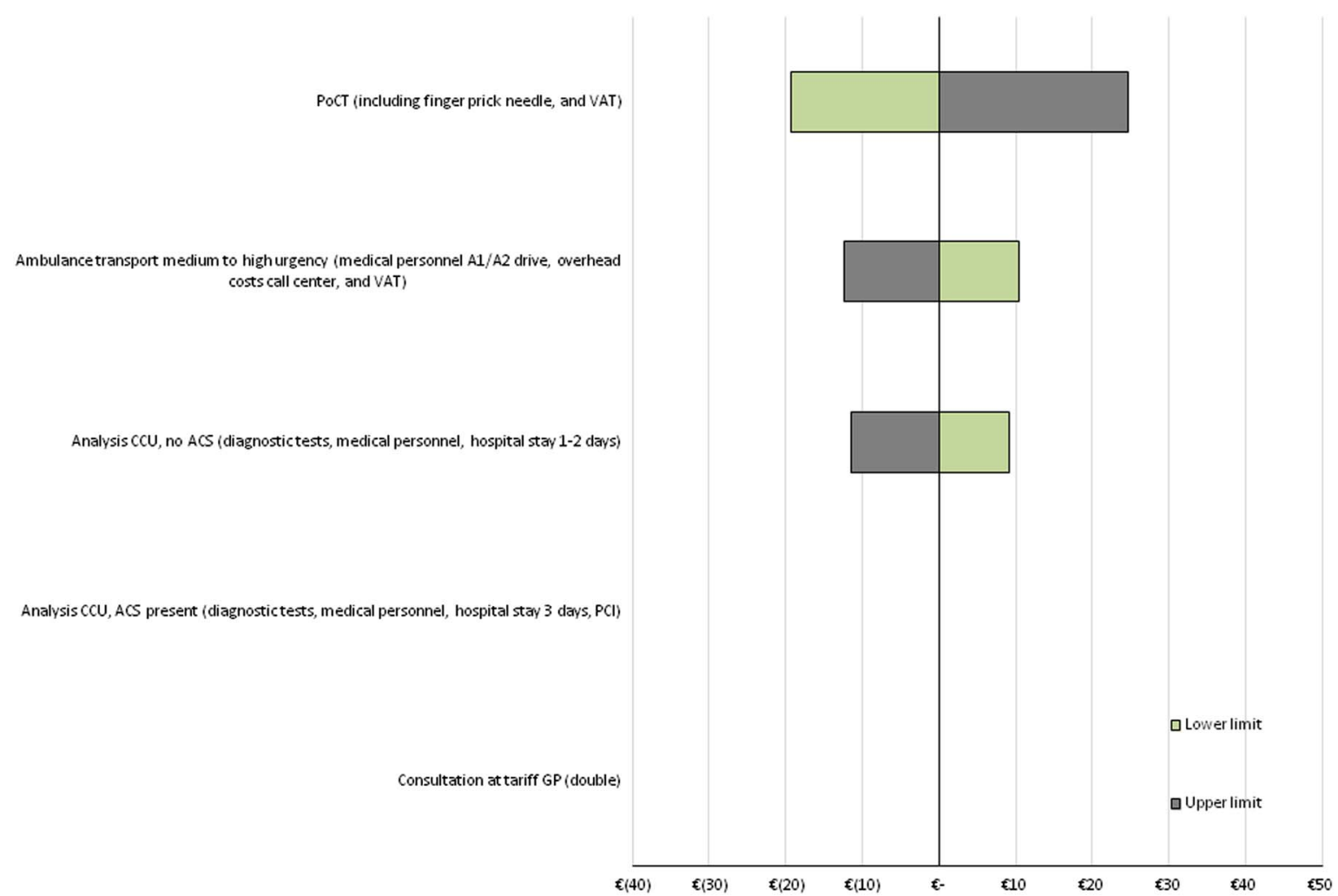

Figure 3 Tornado diagram of one-way SA's for 'international data'. Tornado diagram showing the impact of changes in input parameters on the difference in costs, based on 'international data'. Costs of a PoCT are set at $€ 45$, and the reduction of ACS negative referrals (FPs) is assumed to be $29.0 \%$ (cost-neutral situation as compared with current practice, see Figure 1). All input parameters were varied with $25 \%$ below and above the mean value. ACS $=$ acute coronary syndrome; $\mathrm{CCU}=$ coronary care unit; $\mathrm{FPs}=$ false positives; $\mathrm{PCl}=$ percutaneous coronary intervention; one-way $\mathrm{SA}=$ one-way sensitivity analysis; $\mathrm{PoCT}=$ point-of-care test; VAT = value-added tax.

analysis, as this allows to apply the model to a wider range of PoCT cardiac markers for use in primary care.

\section{Strength and weakness}

A strength of this study is that, to our knowledge, this study is the first to describe the possible financial benefit of a CDR incorporating a PoCT in chest pain patients presenting in primary care. We synthesized all available and relevant evidence, from different studies and countries, to make the best possible estimation of prevalence of chest complaints and referral rates in primary care. Moreover, we repeated the analysis using three different data sets for patient numbers of chest pain patients in primary care in the health economic model. As the base case model outcome is based on several international studies, it is likely that the results regarding the effectiveness can be generalized to other countries. However, as costs may differ strongly between countries, countryspecific cost estimates are required to make reliable per-country calculations.

In our analyses it was assumed that the test is performed in all patients. However, when a CDR is already positive after only scoring a patient's clinical findings by the GP, the patient will most likely be immediately referred without performing a PoCT. Therefore, as the use of PoCT will likely be more sophisticated in daily clinical practice, the costs of PoCT have (conservatively) been 
overestimated in the current analysis. On the other hand, wide availability of a validated PoCT in the future could lower the threshold for using this test in daily practice, as expected based on previous research (Kip et al., 2017).

Still, some uncertainties remain. Despite the fact that patient numbers and referral rates are based on a thorough review of available literature, the number of studies that could eventually be included was limited for some model input parameters. In addition, some of those studies were relatively small. Although it might have been most straightforward to use a Dirichlet distribution to estimate all four probabilities (TP, FP, TN and FN) simultaneously, this would have required to use a small number of patients across this distribution, thereby largely overestimating the uncertainty in model outcomes. Therefore, a Beta distribution was used instead, which allows a two-step approach. First, the probability of a patient being referred was estimated (which was based on a large number of patients), followed by estimating the probability of being either TP or FP (among referrals), or TN or FN (among non-referrals). As we assumed that the number of patients with and without ACS had to remain constant, patients could only switch from TP to FN, and from TN to FP (and vice versa). Consequently, we could not simultaneously incorporate uncertainty in the number of patients that either have or do not have ACS. However, as the result of Monte Carlo simulations shows that the uncertainty in costs is expected to be limited, and because the analysis has been performed for three different scenarios, we consider it unlikely that incorporating this uncertainty would have changed the conclusions.

Furthermore, a validated CDR does not yet exist and until such a diagnostic tool is available, the actual diagnostic performance of a CDR incorporating a POCT remains uncertain. In addition, an issue that could not be included in the current model (as it was considered too complex for the scope of this analysis), is the possible presence of other severe diseases causing chest pain in patients where ACS is excluded. However, in recent studies, nearly all FPs are diagnosed with not life threatening diseases (Bruins Slot et al., 2013; Hoorweg et al., 2017). Another possible limitation may be caused by the fact that the number of FNs was assumed to remain constant in the current analysis. In current practice, patients that are initially not referred but are eventually diagnosed as having ACS (in the following days after assessment by a GP) might be under registered. Moreover, a PoCT could reduce FN referrals, which likely leads to health gain. In addition, those $\mathrm{FN}$ rates were found to be relatively high in our 'international data' set, but appear to be much lower in recent studies (Hoorweg et al., 2017), and based on the authors' experience in daily clinical practice. Therefore, the 'combined' data set is assumed to provide an estimate better reflecting current practice in the Netherlands, and in many other countries with similar healthcare systems. However, because of the assumptions that had to be made, the 'international' data were conservatively chosen as base case scenario in the current analysis.

\section{Conclusion}

If the use of a CDR including a PoCT can reduce unnecessary referrals of chest pain patients to secondary care, this could considerably reduce healthcare costs. Our study provides insights in the minimum requirements (regarding the relative reduction in FPs, as well as the costs of the PoCT) for the CDR strategy including a PoCT to become cost-saving.

\section{Acknowledgements}

The authors thank VGZ health insurance for their assistance in determination of cost prices of cardiac care in secondary care facilities. They thank GGD Zuid-Limburg for their assistance in determination of cost prices of ambulance transport.

\section{Financial Support}

The study is funded by means of an unrestricted grant by FABPulous BV, the company that develops point-of-care H-FABP-tests. FABPulous BV had no role in data collection, data management, data analysis or interpretation of data. Publication of possible unfavorable outcome of our study was guaranteed.

\section{Conflicts of Interest}

J.G. is chief scientific officer (CSO) at FABPulous $\mathrm{BV}$. The remaining authors report no conflicts of 
interest. The authors alone are responsible for the content and writing of the paper.

\section{Supplementary material}

To view supplementary material for this article, please visit https://doi.org/10.1017/S146342361700069X

\section{References}

Academic Hospital Maastricht. 2013: Data derived from analysis of registration data Academic Hospital Maastricht.

Andersson, P.O., Karlsson, J.E., Landberg, E., Festin, K. and Nilsson, S. 2015: Consequences of high-sensitivity troponin $\mathrm{T}$ testing applied in a primary care population with chest pain compared with a commercially available point-of-care troponin $\mathrm{T}$ analysis: an observational prospective study. BioMed Central Research Notes 8, 210.

Bakx, C., Schwarte, J., Van Den Hoogen, H., Bor, H. and Van Weel, C. 2005: First myocardial infarction in a Dutch general practice population: trends in incidence from 1975-2003. British Journal of General Practice 55, 860-63.

Body, R., Carley, S., Wibberley, C., Mcdowell, G., Ferguson, J. and Mackway-Jones, K. 2010: The value of symptoms and signs in the emergent diagnosis of acute coronary syndromes. Resuscitation 81, 281-86.

Bosner, S., Becker, A., Haasenritter, J., Abu Hani, M., Keller, H., Sonnichsen, A.C., Karatolios, K., Schaefer, J.R., Seitz, G., Baum, E. and Donner-Banzhoff, N. 2009: Chest pain in primary care: epidemiology and pre-work-up probabilities. European Journal of General Practice 15, 141-46.

Bosner, S., Bonisch, K., Haasenritter, J., Schlegel, P., Hullermeier, E. and Donner-Banzhoff, N. 2013: Chest pain in primary care: is the localization of pain diagnostically helpful in the critical evaluation of patients? A cross sectional study. BioMed Central Family Practice 14, 154.

Briggs, A., Sculpher, M.J. and Claxton, K. 2006: Decision modelling for health economic evaluation. Oxford: Oxford University Press.

Bruins Slot, M.H., Rutten, F.H., Van Der Heijden, G.J., Doevendans, P.A., Mast, E.G., Bredero, A.C., Van Der Spoel, O.P., Glatz, J.F. and Hoes, A.W. 2013: Diagnostic value of a heart-type fatty acid-binding protein (H-FABP) bedside test in suspected acute coronary syndrome in primary care. International Journal of Cardiology 168, 1485-489.

Buntinx, F., Knockaert, D., Bruyninckx, R., De Blaey, N., Aerts, M., Knottnerus, J.A. and Delooz, H. 2001: Chest pain in general practice or in the hospital emergency department: is it the same? Family Practice 18, 586-89.

Cals, J.W., Ament, A.J., Hood, K., Butler, C.C., Hopstaken, R. M., Wassink, G.F. and Dinant, G.J. 2011: C-reactive protein point of care testing and physician communication skills training for lower respiratory tract infections in general

Primary Health Care Research \& Development 2018; 19: 176-188 practice: economic evaluation of a cluster randomized trial. Journal of Evaluation in Clinical Practice 17, 1059-69.

Carroll, K., Majeed, A., Firth, C. and Gray, J. 2003: Prevalence and management of coronary heart disease in primary care: population-based cross-sectional study using a disease register. Journal of Public Health Medicine 25, 29-35.

Catholic University Leuven. 2013: Derived from analysis of registration data Catholic University Leuven.

Centraal Bureau voor de Statistiek (CBS). 2014a: Cardiovascular mortality. Retrieved 10 July 2015 from http://statline. cbs.nl/Statweb/publication/?DM=SLNL\&PA=7233\&D1= $655-659 \& \mathrm{D} 2=0 \& \mathrm{D} 3=0 \& \mathrm{D} 4=0,4,9,(\mathrm{I}-1)-\mathrm{I} \& \mathrm{VW}=\mathrm{T}$.

Centraal Bureau voor de Statistiek (CBS). 2014b: Inhabitants the Netherlands. Retrieved 10 July 2015 from http://www.cbs. $\mathrm{nl} / \mathrm{nl}-\mathrm{NL} / \mathrm{menu} /$ themas/bevolking/cijfers/extra/bevolkingsteller. htm.

Centraal Bureau voor de Statistiek (CBS). 2014c: GP visits in The Netherlands. Retrieved 10 July 2015 from http:// statline.cbs.nl/StatWeb/publication/?VW=T\&DM=SLNL\& $\mathrm{PA}=81178 \mathrm{NED} \& \mathrm{D} 1=0-2,12-14,25-27,41,46,53 \& \mathrm{D} 2=\mathrm{a} \& \mathrm{D} 3$ $=\mathrm{a} \& \mathrm{D} 4=0 \& \mathrm{D} 5=1 \& \mathrm{HD}=130701-1102 \& \mathrm{HDR}=\mathrm{G} 4, \mathrm{G} 3, \mathrm{~T} \&$ $\mathrm{STB}=\mathrm{G} 1, \mathrm{G} 2$ and http://www.cbs.nl/nl-NL/menu/themas/ gezondheid-welzijn/publicaties/artikelen/archief/2013/20133854-wm.htm.

Centraal Bureau voor de Statistiek (CBS). 2014d: Causes of death in The Netherlands. Retrieved 10 July 2015 from http:// statline.cbs.nl/StatWeb/selection/default.aspx?VW=T\& $\mathrm{DM}=\mathrm{SLNL} \& \mathrm{PA}=7052 \_95 \& \mathrm{D} 1=0 \% 2 \mathrm{c} 79-91 \& \mathrm{D} 2=0 \& \mathrm{D} 3=0$ $\& D 4=a \& H D R=G 1 \% 2 c G 2 \% 2 c G 3 \& S T B=T$.

Centraal Bureau voor de Statistiek (CBS). 2016: Consumentenprijzen; prijsindex 2006 $=100$ [Online]. Den Haag/Heerlen. Retrieved 31 March 2016 from http://statline.cbs.nl/Statweb/ publication/?DM $=$ SLNL\&PA $=71311 \mathrm{NED} \& \mathrm{D} 1=0 \& \mathrm{D} 2=0 \&$ D3=64,77,90,103,116,129,142,155,168,181,194,219,232,245, $258,1 \& H D R=G 1, T \& S T B=G 2 \& V W=T$.

Chambers, J. and Bass, C. 1998: Atypical chest pain: looking beyond the heart. QJM 91, 239-44.

Dumville, J.C., Macpherson, H., Griffith, K., Miles, J.N. and Lewin, R.J. 2007: Non-cardiac chest pain: a retrospective cohort study of patients who attended a Rapid Access Chest Pain Clinic. Family Practice 24, 152-57.

Dutch Heart Foundation. 2013: Percentage of patients with AMI in an emergency department. Data from Dutch Heart Foundation. Retrieved 10 July 2015 from http://www. hartstichting.nl/hart-en-vaatziekten/feiten-en-cijfers-hart-envaatziekten.

Frese, T., Mahlmeister, J., Heitzer, M. and Sandholzer, H. 2016: Chest pain in general practice: Frequency, management, and results of encounter. Journal of Family Medicine and Primary Care 5, 61-66.

Geersing, G.J., Erkens, P.M., Lucassen, W.A., Buller, H.R., Cate, H.T., Hoes, A.W., Moons, K.G., Prins, M.H., Oudega, R., Van Weert, H.C. and Stoffers, H.E. 2012: Safe exclusion of pulmonary embolism using the Wells rule and qualitative D-dimer testing in primary care: prospective cohort study. British Medical Journal 345, e6564. 
Gencer, B., Vaucher, P., Herzig, L., Verdon, F., Ruffieux, C., Bosner, S., Burnand, B., Bischoff, T., Donner-Banzhoff, N. and Favrat, B. 2010: Ruling out coronary heart disease in primary care patients with chest pain: a clinical prediction score. BioMed Central Medicine 8, 9.

Glatz, J.F. and Mohren, R. 2013: Plasma reference value of heart-type fatty acid binding protein, the earliest available plasma biomarker of acute myocardial infarction. Health 5, 1206-209.

Glatz, J.F. and Renneberg, R. 2014: Added value of heart-type fatty acid-binding protein as plasma marker for the early evaluation of suspected acute coronary syndrome. Clinical Lipidology 9, 205-20.

Graff, L.G., Dallara, J., Ross, M.A., Joseph, A.J., Itzcovitz, J., Andelman, R.P., Emerman, C., Turbiner, S., Espinosa, J.A. and Severance, H. 1997: Impact on the care of the emergency department chest pain patient from the chest pain evaluation registry (CHEPER) study. American Journal of Cardiology 80, 563-68.

Grijseels, E.W., Deckers, J.W., Hoes, A.W., Boersma, E., Hartman, J.A., Van Der Does, E. and Simoons, M.L. 1996: Implementation of a pre-hospital decision rule in general practice. Triage of patients with suspected myocardial infarction. European Heart Journal 17, 89-95.

Haasenritter, J., Biroga, T., Keunecke, C., Becker, A., DonnerBanzhoff, N., Dornieden, K., Stadje, R., Viniol, A. and Bosner, S. 2015: Causes of chest pain in primary care - a systematic review and meta-analysis. Croatian Medical Journal 56, 422-30.

Haasenritter, J., Bosner, S., Vaucher, P., Herzig, L., HeinzelGutenbrunner, M., Baum, E. and Donner-Banzhoff, $\mathbf{N}$. 2012: Ruling out coronary heart disease in primary care: external validation of a clinical prediction rule. British Journal of General Practice 62, e415-421.

Hocaoglu, C., Gulec, M.Y. and Durmus, I. 2008: Psychiatric comorbidity in patients with chest pain without a cardiac etiology. Israelian Journal of Psychiatry and Related Sciences 45, 49-54.

Hoorweg, B.N., Willemsen, R.T., Cleef, L.E., Boogaerts, T., Buntinx, F., Glatz, J.F. and Dinant, G.J. 2017: Frequency of chest pain in primary care, diagnostic tests performed and final diagnoses. Heart 103, 1727-32.

Kip, M.M.A., Noltes, A.M., Koffijberg, H., IJzerman, M.J. and Kusters, R. 2017: Improving early exclusion of acute coronary syndrome in primary care: the added value of point-of-care troponin as stated by general practitioners. Primary Health Care Research \& Development 18, 386-97.

Klinkman, M.S., Stevens, D. and Gorenflo, D.W. 1994: Episodes of care for chest pain: a preliminary report from MIRNET. Michigan Research Network. Journal of Family Practice 38, 345-52.

Koek, H.L., De Bruin, A., Gast, A., Gevers, E., Kardaun, J.W., Reitsma, J.B., Grobbee, D.E. and Bots, M.L. 2007: Incidence of first acute myocardial infarction in the Netherlands. Netherlands Journal of Medicine 65, 434-41.
Kohn, M.A., Kwan, E., Gupta, M. and Tabas, J.A. 2005: Prevalence of acute myocardial infarction and other serious diagnoses in patients presenting to an urban emergency department with chest pain. Journal of Emergency Medicine 29, 383-90.

Little, P., Stuart, B., Francis, N., Douglas, E., Tonkin-Crine, S., Anthierens, S., Cals, J.W., Melbye, H., Santer, M., Moore, M., Coenen, S., Butler, C., Hood, K., Kelly, M., GodyckiCwirko, M., Mierzecki, A., Torres, A., Llor, C., Davies, M., Mullee, M., O'Reilly, G., Van Der Velden, A., Geraghty, A. W., Goossens, H., Verheij, T. and Yardley, L., GRACE Consortium. 2013: Effects of internet-based training on antibiotic prescribing rates for acute respiratory-tract infections: a multinational, cluster, randomised, factorial, controlled trial. Lancet 382, 1175-182.

Mourad, G., Alwin, J., Stromberg, A. and Jaarsma, T. 2013: Societal costs of non-cardiac chest pain compared with ischemic heart disease - a longitudinal study. BioMed Central Health Services Research 13, 403.

Nilsson, S., Andersson, P.O., Borgquist, L., Grodzinsky, E., Janzon, M., Kvick, M., Landberg, E., Nilsson, H. and Karlsson, J.E. 2013: Point-of-care troponin T testing in the management of patients with chest pain in the Swedish primary care. International Journal of Family Medicine 2013, 532093.

Nilsson, S., Scheike, M., Engblom, D., Karlsson, L. G., Molstad, S., Akerlind, I., Ortoft, K. and Nylander, E. 2003: Chest pain and ischaemic heart disease in primary care. British Journal of General Practice 53, 378-82.

Okkes, I.M., Oskam, S.K., Van Boven, K. and Lamberts, H. 2005: Episodes of care in family practice. Epidemiological data based on the routine use of the International Classification of Primary Care (ICPC) in the Transition Project of the Academic Medical Center/University of Amsterdam. ICPC in the AmsterdamTransition Project. Amsterdam: Academic Medical Center / University of Amsterdam.

Rosser, W., Henderson, R., Wood, M. and Green, L.A. 1990: An exploratory report of chest pain in primary care. A report from ASPN. Journal of the American Board of Family Practice 3, 143-50.

Ruigomez, A., Rodriguez, L.A., Wallander, M.A., Johansson, S. and Jones, R. 2006: Chest pain in general practice: incidence, comorbidity and mortality. Family Practice 23, 167-74.

Soler, J.K., Okkes, I., Oskam, S., Van Boven, K., Zivotic, P., Jevtic, M., Dobbs, F. and Lamberts, H. 2012a: An international comparative family medicine study of the Transition Project data from the Netherlands, Malta and Serbia. Is family medicine an international discipline? Comparing diagnostic odds ratios across populations. Family Practice 29, 299-314.

Soler, J.K., Okkes, I., Oskam, S., Van Boven, K., Zivotic, P., Jevtic, M., Dobbs, F. and Lamberts, H., Transition Project 2012b: An international comparative family medicine study of the Transition Project data from the Netherlands, Malta 
and Serbia. Is family medicine an international discipline? Comparing incidence and prevalence rates of reasons for encounter and diagnostic titles of episodes of care across populations. Family Practice 29, 283-98.

Sox, H.C. Jr., Hickam, D.H., Marton, K.I., Moses, L., Skeff, K. M., Sox, C.H. and Neal, E.A. 1990: Using the patient's history to estimate the probability of coronary artery disease: a comparison of primary care and referral practices. American Journal of Medicine 89, 7-14.

Svavarsdottir, A.E., Jonasson, M.R., Gudmundsson, G.H. and Fjeldsted, K. 1996: Chest pain in family practice. Diagnosis and long-term outcome in a community setting. Canadian Family Physician 42, 1122-128.

Verdon, F., Herzig, L., Burnand, B., Bischoff, T., Pecoud, A., Junod, M., Muhlemann, N. and Favrat, B. 2008: Chest pain in daily practice: occurrence, causes and management. Swiss Medical Weekly 138, 340-47.

Willemsen, R.T., Buntinx, F., Winkens, B., Glatz, J.F. and Dinant, G.J. 2014: The value of signs, symptoms and plasma heart-type fatty acid-binding protein (H-FABP) in evaluating patients presenting with symptoms possibly matching acute coronary syndrome: background and methods of a diagnostic study in primary care. BioMed Central Family Practice 15, 203.

Willemsen, R.T., Van Severen, E., Vandervoort, P.M., Grieten, L., Buntinx, F., Glatz, J.F. and Dinant, G.J. 2015: Heart-type fatty acid binding protein (H-FABP) in patients in an emergency department setting, suspected of acute coronary syndrome: optimal cut-off point, diagnostic value and future opportunities in primary care. European Journal of General Practice 21, 156-63.

Winters, M.E. and Katzen, S.M. 2006: Identifying chest pain emergencies in the primary care setting. Primary Care 33, 625-42.

Yeh, R.W., Sidney, S., Chandra, M., Sorel, M., Selby, J.V. and Go, A.S. 2010: Population trends in the incidence and outcomes of acute myocardial infarction. New England Journal of Medicine 362, 2155-165. 